\title{
Seminal plasma AnnexinA2 protein is a relevant biomarker for stallions which require removal of seminal plasma for sperm survival upon refrigeration
}

Gemma Gaitskell-Phillips, Francisco E. Martin-Cano, Jose M. Ortiz-Rodriguez, Antonio Silva-Rodriguez, Heriberto Rodriguez-Martinez, Maria C. Gil, Cristina Ortega-Ferrusola and Fernando J. Pena

The self-archived postprint version of this journal article is available at Linköping University Institutional Repository (DiVA):

http://urn.kb.se/resolve?urn=urn:nbn:se:liu:diva-173015

N.B.: When citing this work, cite the original publication.

Gaitskell-Phillips, G., Martin-Cano, F. E., Ortiz-Rodriguez, J. M., Silva-Rodriguez, A., RodriguezMartinez, H., Gil, M. C., Ortega-Ferrusola, C., Pena, F. J., (2020), Seminal plasma AnnexinA2 protein is a relevant biomarker for stallions which require removal of seminal plasma for sperm survival upon refrigeration, Biology of Reproduction, 103(6), 1275-1288. https://doi.org/10.1093/biolre/ioaa153

Original publication available at:

https://doi.org/10.1093/biolre/ioaa153

Copyright: Society for the Study of Reproduction http://www.ssr.org/ 


\section{Seminal plasma AnnexinA2 protein is a relevant biomarker for stallions which require removal of seminal plasma for sperm survival upon refrigeration}

${ }^{1}$ Gemma Gaitskell-Phillips, ${ }^{1}$ Francisco E. Martín-Cano FE, ${ }^{1}$ José M Ortiz-Rodríguez, ${ }^{2}$ Antonio Silva-Rodríguez, ${ }^{3}$ Heriberto Rodríguez-Martínez ${ }^{1}$ Maria C. Gil, ${ }^{1}$ Ortega-Ferrusola C, ${ }^{1 *}$ Fernando J. Peña

${ }^{1}$ Laboratory of Equine Reproduction and Equine Spermatology, Veterinary Teaching Hospital, University of Extremadura, Cáceres, Spain.

2 Facility of Innovation and Analysis in Animal Source Foodstuffs, University of Extremadura, Cáceres, Spain.

${ }^{3}$ Department of Biomedical and Clinical Sciences (BKV), Faculty of Medicine \& Health Sciences, Linköping University, Linköping, Sweden

*Correspondence to Dr. FJ Peña, Veterinary Teaching Hospital, Laboratory of Equine Spermatology and Reproduction, Faculty of Veterinary Medicine University of Extremadura Avd. de la Universidad s/n 10003 Cáceres Spain. E-mail fjuanpvega@unex.es

phone +34 927-257167

fax +34927257102

\section{Acknowledgements}

The authors received financial support for this study from the Ministry of Science-FEDER, Madrid, Spain, grants, AGL2017-83149-R Junta de Extremadura-FEDER (GR 18008 and IB16030). JMOR holds a PhD grant from the Junta de Extremadura- FEDER (PD 18005), Mérida, Spain. GLGF holds a PhD grant from the Ministry of Science, Madrid, Spain (PRE2018-083354).

\section{Abstract}

Some stallions yield ejaculates which do not tolerate conservation in the liquid state pending artificial insemination (Al), improving after removal of most of the seminal plasma (SP) by centrifugation. Here, the SP-proteome of 10 different stallions was defined through HPLC/MS/MS and bioinformatic analysis in relation to their ability of ejaculates to withstand conservation in refrigeration. Pathway enrichment analysis using human orthologs was performed using g:profiler showing enriched Reactome and KEGG pathways related to hexose metabolism, vesicle mediated transport post translational modification of proteins and the immune response. Specific proteins overrepresented in both groups of good stallions included a peroxiredoxin-6 like protein, and transcobalamin-2, a primary vitamin B12-binding and transport protein. Also, the 
protein involved in protein glycosylation, ST3 beta-galactoside alpha-2,3sialyltransferase 1 was present in the GOOD stallions. These proteins were nearly absent in POOR stallions. Particularly, annexinA2 appeared as the most powerful discriminant variable to identify stallions needing SP-removal prior to refrigeration, with a $p=0.002$ and a q value $=0.005$. Overall this is the first detailed study of the equine SP-proteome, showing its potential value of specific proteins as discriminant bio-markers to clinically classify stallions for Al.

Key words: seminal plasma, UHPLC/MS/MS, proteins, artificial insemination, horse.

\section{Introduction}

Despite artificial insemination (Al) being successfully used in equine breeding, few drawbacks exclude valuable stallions from wider use in Al with refrigerated, extended semen, since their semen does not tolerate storage [1]. However, ejaculates from many of these stallions improve preservation when most of the seminal plasma (SP) is removed by centrifugation [2,3], suggesting something in the SP plays a part in how tolerant the ejaculate is of being stored in the liquid state [4]. Seminal plasma in stallions is composed of the secretions of the epididymis and the accessory glands of the male genital tract, particularly from the prostate. Stallions produce ejaculates with large volumes and the SP is involved in different functions, from acting as a vehicle, nourishing and regulating spermatozoa viability [5-9] to interactions with the mare's endometrium $[5,10-12]$. Although many proteins in equine SP have been previously characterized [6, 13-19], detailed proteomic studies of the equine SP using shot gun proteomics are not available as yet. The use of different 'omics is rapidly advancing our knowledge of sperm biology [20-24], and despite the importance of proteomics, it is a relatively recent field in spermatology and, in the particular case of equines, only two papers have been published to date using shot gun proteomics $[25,26]$, although there is a previous paper addressing the proteome of the equine seminal plasma [18]. Nevertheless, proteomic studies are providing striking. Owing to the enormous need to link novel findings on sperm biology, including the complexity and plasticity of their metabolism and the presence of proteins involved in transcription and translation $[20,27,28]$ suggesting a role in early embryo development; the present study tested the hypothesis that specific bio-markers for the ability of ejaculates to withstand refrigeration for Al can be detected in equine SP.

\section{MATERIAL AND METHODS}

\section{Reagents and media}

All chemicals were purchased from Sigma-Aldrich (Madrid, Spain), unless otherwise stated.

\section{Semen collection and processing}


Semen was collected from 10 stallions maintained as indicated under European regulations for animal care (Law 6/2913 June 11th and European Directive 2010/63/EU). The study was supervised and approved by the ethical committee of the University. Semen collection was carried out using a warmed Missouri model artificial vagina following standard protocols at our center, using a filter to separate the gel fraction. Upon arrival at the laboratory, the ejaculate was processed using colloidal centrifugation $[29,30]$ to isolate SP.

\section{Experimental design}

Three ejaculates from each of 10 stallions with different ability to withstand semen extension and centrifugation for Al were used in this study. Additional independent ejaculates from the same stallions were used for sperm functional analysis, and an aliquot from the same ejaculate was extended in INRA96 ${ }^{\circledR}$ (IMV Technologies, L'Aigle, France) and was kept refrigerated at $4{ }^{\circ} \mathrm{C}$ for $48 \mathrm{~h}$. The remaining aliquot was processed by centrifugation to remove the bulk of SP and then extended in INRA $96 \AA$ and kept refrigerated at $4 \stackrel{\circ}{\circ}$ for $48 \mathrm{~h}$. After 24 and 48 hours of incubation, sperm motility and velocities were measured in both groups (with and without seminal plasma) using computer assisted sperm analysis (CASA). Based on this analysis stallions were classified into three groups: good if motility after $48 \mathrm{~h}$ was $>50 \%$ and $\mathrm{VCL}$ was $>100 \mu \mathrm{m} / \mathrm{s}$, poor if motility after $48 \mathrm{~h}$ was $<50 \%$ and $\mathrm{VCL}$ was $<100 \mu \mathrm{m} / \mathrm{s}$ and good after removal of seminal plasma (RSP), if after centrifugation and removal of the bulk of seminal plasma motility after $48 \mathrm{~h}$ was $>50 \%$ and VCL was $>100 \mu \mathrm{m} / \mathrm{s}$.

\section{Sample preparation}

Aliquots of isolated SP were kept frozen at -80 ㅇ C until further analysis. Phase contrast microscopy was used to control the absence of spermatozoa, moreover SP was filtered $(0.22 \mu \mathrm{M})$ before further processing.

\section{Protein solubilization}

Aliquots of SP were solubilized in lysis buffer (C7:C7BzO [3-(4-heptyl) phenyl-( 3hydroxypropyl) dimethylammoniopropanesulfonate], $7 \mathrm{M}$ urea, $2 \mathrm{M}$ thiourea and $40 \mathrm{mM}$ Tris ( $\mathrm{pH}$ 10.4), incubated under constant rotation at -4 으 $\mathrm{C}$ for 1 hour.

\section{Protein quantification}

Protein quantification was performed using the 2-D Quant Kit (GE Healthcare, Sevilla Spain) following the manufacturer's instructions: https://www.gelifesciences.co.jp/tech support/manual/pdf/80648622.pdf. All samples were normalized to obtain a final concentration of $100 \mu \mathrm{g}$ of protein per sample.

\section{In-solution trypsin digestion.}

$200 \mu \mathrm{L}$ of solution obtained from the previous stage were mixed with $100 \mu \mathrm{l}$ of $25 \mathrm{mM}$ ammonium bicarbonate buffer $\mathrm{pH} 8.5(100 \mu \mathrm{g}$ of protein in $300 \mu \mathrm{L}$ of solution). The 
addition of $30 \mu \mathrm{L}$ of $10 \mathrm{mM}$ DTT was used to reduce the proteins under incubation at 56 ${ }^{\circ} \mathrm{C}$ for $20 \mathrm{~min}$. The proteins were then alkylated by adding $30 \mu \mathrm{L}$ of $20 \mathrm{mM}$ IAA and incubated for $30 \mathrm{~min}$ at room temperature in the dark. Finally, digestion was performed by adding $1 \mu \mathrm{L}$ of Trypsin Proteomics Grade (Sigma) (Trypsin solution: $1 \mu \mathrm{g} / \mu \mathrm{L}$ in $1 \mathrm{mM}$ $\mathrm{HCl}$ ) at $37{ }^{\circ} \mathrm{C}$ for at least $3 \mathrm{~h}$ to overnight. The reaction was stopped adding $10 \mu \mathrm{L}$ of $0.1 \%$ formic acid and the solution filtered through $0.2 \mu \mathrm{m}$ (hydrophilic PTFE) to a $2 \mathrm{~mL}$ dark glass vial. In the last step the samples were dried using a constant nitrogen current with the vial in a heating block at 35ㅇ․ The dry samples were resuspended in $20 \mu \mathrm{l}$ of buffer A, consisting of water/acetonitrile/formic acid (94.9:5:0.1)

\section{UHPLC-MS/MS analysis.}

The UHPLC/MS system used was an Agilent 1290 Infinity II Series UHPLC (Agilent Technologies, Santa Clara, CA, USA) equipped with an automated multisampler module and a High Speed Binary Pump coupled to an Agilent 6550 Q-TOF Mass Spectrometer (Agilent Technologies, Santa Clara, CA, USA) using an Agilent Jet Stream Dual electrospray (AJS-Dual ESI) interface. The MassHunter Workstation Data Acquisition software (Agilent Technologies, Rev. B.06.01) controlled the UHPLC and Q-TOF. Every sample was injected onto an Agilent AdvanceBio Peptide Mapping HPLC column (2.7 $\mu \mathrm{m}, 150 \times 2.1 \mathrm{~mm}$, Agilent technologies), thermostatted at $55^{\circ} \mathrm{C}$, at a flow rate of 0.4 $\mathrm{ml} / \mathrm{min}$. The gradient program started with $2 \%$ of buffer $B$ (water/acetonitrile/formic acid, 10:89.9:0.1) that remained in isocratic mode for $5 \mathrm{~min}$ and then increased linearly up to $45 \%$ B over $40 \mathrm{~min}$, further increasing up to $95 \%$ B for $15 \mathrm{~min}$ and remaining constant for an additional $5 \mathrm{~min}$. After this $70 \mathrm{~min}$ run, $5 \mathrm{~min}$ of post-time followed using the initial condition for conditioning of the column for the next run. The mass spectrometer was operated in the positive mode. The nebulizer gas pressure was set to $35 \mathrm{psi}$, whereas the drying gas flow was set to $10 \mathrm{l} / \mathrm{min}$ at $250^{\circ} \mathrm{C}$. The sheath gas flow was set to $300 \stackrel{\circ}{ } \mathrm{C}$. The peak to peak voltages of the capillary spray, fragmentor and octopole RF were $3500 \mathrm{~V}, 340 \mathrm{~V}$ and $750 \mathrm{~V}$ respectively. Profile data were acquired for both MS and MS/MS scans in extended dynamic range mode, where the MS and MS/MS mass ranges were $50-1700 \mathrm{~m} / \mathrm{z}$ and scan rates were 8 spectra/sec for MS and 3 spectra/sec for MS/MS. Auto MS/MS mode was used with precursor selection by abundance and a maximum of 20 precursors selected per cycle. A ramped collision energy was used with a slope of 3.6 and an offset of -4.8 . The same ion was rejected after two consecutive scans.

\section{Data processing}

Data processing and analysis was performed using Spectrum Mill MS Proteomics Workbench (Rev B.04.01, Agilent Technologies, Santa Clara, CA, USA). Briefly, raw data were extracted under default conditions as follows: non fixed or variable modifications were selected; $[\mathrm{MH}]+50-10000 \mathrm{~m} / \mathrm{z}$; maximum precursor charge +5 ; retention time and $\mathrm{m} / \mathrm{z}$ tolerance \pm 60 seconds; minimum signal-to-noise $\mathrm{MS}(\mathrm{S} / \mathrm{N}) 25$; finding ${ }^{12} \mathrm{C}$ signals. The MS/MS search against the appropriate and updated protein database ( https://www.uniprot.org/uniprot/?query=Equus+caballus\&sort=score) was performed following these criteria: non fixed modifications were selected, as variable modifications the following were selected: carbamidomethylated cysteines, tryptic 
digestion with a maximum of 5 missed cleavages, ESI-Q-TOF instrument, minimum matched peak intensity $50 \%$, maximum ambiguous precursor charge +5 , monoisotopic masses, peptide precursor mass tolerance $20 \mathrm{ppm}$, product ion mass tolerance $50 \mathrm{ppm}$, and calculation of reversed database scores. Validation of peptide and protein data was performed using auto thresholds with a \%FR (false discovery rate) of $1.2 \%$. The result for proteins were obtained as protein summarized using all validations; score $>4$ and $\%$ SPI (Scored Peak Intensity: the percentage of the extracted spectrum that is explained by the database search result) 60 .

\section{Sperm proteome analysis}

The proteins identified in SP were queried for gene ontology (GO) terms (http://geneontology.org) according to cellular component (CC), biological process (Bp) and molecular function (MF) and classified using (PANTHER v.14.0) (http://www.pantherdb.org), and g:Profiler (https://biit.cs.ut.ee/gprofiler/gost) following detailed published protocols [31-33]. The lists of proteins were queried against the equine proteome database (https://www.uniprot.org) for significant enrichment using the Fisher's exact test corrected with a False Discovery Rate (FDR) set at $P<0.05$.

\section{Enrichment analysis of pathways in the seminal plasma proteome}

PANTHER pathways (http://www.pantherdb.org/pathway/pathwayList.jsp) and KEGG pathways (https://www.genome.jp/kegg/) [34-37] analysis were used to identify biological pathways likely to be active in seminal plasma. The significance of the presence of the protein list was queried against the equine genome database using a FDR $<0.05$ and Fisher's exact test. g:Profiler was also used to perform an enrichment analysis [33]. Due to the increased depth of the human proteome in terms of annotation, the equine annotations were transformed to their human orthologs using g:Profiler (https://biit.cs.ut.ee/gprofiler/orth) and a pathway enrichment analysis and visualization was performed again using g:Profiler and Cytoscape analysis using Reactome (https://reactome.org).

\section{Network analysis}

STRING was used to analyze the internal structure of the functional network of the seminal plasma proteins identified. Data included co-expression, genetic fusion, cooccurrence of protein-protein interactions among others. A very high confidence threshold $(0.900)$ was selected for interaction between pairs of proteins.

\section{Identification of discriminant proteins in the seminal plasma}

Qlucore Omics Explorer (Lund, Sweden https://qlucore.com) was used to compare differences in the relative amounts of proteins in the seminal plasma based on spectral counts among stallions classified in function of the life span of their ejaculates under refrigeration. Variance filtering was used to reduce the noise and improve the detection of discriminant variables[38]. The identification of discriminant variables between subgroups of stallions (good, good after removal of seminal plasma, and poor) was done 
fitting a linear model for each variable with the condition of semen lifespan under refrigeration as predictor. The P-values were adjusted for multiple testing with the Benjamini-Hochberg method [39], variables with adjusted $p$ values below 0.1 were considered significant. T-tests between two different conditions were also performed and differences were considered significant when $P<0.05$. Data were $\log _{2}$ transformed and normalized, and comparisons were performed filtered by fold change $>2$.

\section{Computer-assisted Sperm Analysis (CASA)}

Sperm motility and velocities were assessed with Computer-assisted Sperm Analysis (CASA) system (ISAS Proiser, Valencia, Spain) [30, 40]. Samples were loaded into a Leja ${ }^{\circledR}$ chamber with a depth of $20 \mu \mathrm{m}$ (Leja, Amsterdam, The Netherlands) and placed on a warmed stage at $37^{\circ} \mathrm{C}$. Sixty consecutive digitized images obtained using a 10x negative phase-contrast objective (Olympus CX 41) and 500 spermatozoa per sample were then analyzed in random fields. Spermatozoa VAP > $35 \mu \mathrm{m} / \mathrm{s}$ were considered motile. Spermatozoa deviating $<45 \%$ from a straight line were classified as linearly motile. The following parameters were measured: percentages of linear motile spermatozoa, and circular (VCL) straight line (VSL) and average (VAP) velocities in $\mu \mathrm{m} / \mathrm{s}$.

\section{Statistical analysis}

The normality of the data was assessed using the Kolmogorov-Smirnoff test. Paired ttests and One-way ANOVA followed by Dunnett's multiple comparisons test were performed using GraphPad Prism version 7.00 for Mac, La Jolla California USA, (www.graphpad.com).

\section{RESULTS}

Three ejaculates from each of 10 stallions were used in this study, and 3,544 different proteins were identified matched to the equine proteome database. The complete list of SP-proteins is provided as supplementary material (suppl table 1).

\section{Gene ontology analysis of seminal plasma proteins}

Gene ontology (GO) analysis (biological processes BP) of SP-proteins returned enriched terms related to metabolism (Table 1), only terms with a fold enrichment $>2$ are provided. Interestingly, terms related to redox regulation were also present including the terms cellular response to hydrogen peroxide (GO:0070301) and response to hydrogen peroxide (GO:0042542). Gene ontology terms for cellular components (CC) are provided in Table 2 and include terms related to immunological synapse (GO:0001772) responses and extracellular space (GO:0005615) and extracellular region (GO:0005576). The g:profiler analysis of orthologs revealed, in addition to terms related to metabolism, an enrichment in $\mathrm{GO}$ terms (cellular components) related to extracellular vesicles (GO:1903561), extracellular exosome (G0:0070062) and vesicle mediated transport (GO:0016192) (Fig 1.), suggesting a role for SP in promoting cell-to-cell communication. Noteworthy, the term animal organ development (GO:0048513) was observed in the enrichment. 


\section{Pathway enrichment analysis}

The results of the pathway enrichment analysis using g:profiler with human orthologs are given in the Manhattan plot of Fig 2 and accompanying table. Reactome and KEGG pathways related to hexose metabolism, vesicle mediated transport post translational modification of proteins, and pathways related to the immune response were enriched.

\section{Functional network analysis}

STRING analysis revealed functional networks in the equine SP with a protein to protein interaction (PPI) with the highest confidence threshold $(0.900)$ and a $P$ value $=7.06 \mathrm{e}-05$ (Fig 3). Functional enrichment domains included the reactome pathways, glycolysis (FDR $=0.00039)$, vesicle mediated transport (FDR $=0.00039)$, gluconeogenesis (FDR=0.003), neutrophil degranulation (FDR $=0.0051$ ), post-translational protein modification (FDR=0.0051), and binding and uptake of ligands by scavenger receptors (FDR=0.0051).(Fig 3)

\section{Impact of the equine SP-proteome on the preservation of chilled semen}

Stallion ejaculates were collected and evaluated in terms of life span after extension and refrigeration to $5^{\circ} \mathrm{C}$ for $48 \mathrm{~h}$. Three different outcomes were evident (Fig 4); good were those stallions in which total motility and curvilinear velocity $(\mathrm{VCL})$ were $>50 \%$ and 90 $\mu \mathrm{m} / \mathrm{s}$ respectively. Some stallions required SP-elimination to reach these values. This group of stallions were named good after removal of seminal plasma (RSP). Finally, stallions which did not reach these minimum values were classified as poor. The proteome was studied in these three groups, and differences observed between groups with significant differences in the number of proteins over or underrepresented in each group. In particular, numerous proteins were detected as being underrepresented in the poor group of stallions (Fig 5). In order to identify specific proteins in each of the groups that may explain the differences observed, an ANOVA was performed and a heat map constructed (Fig 6), specific proteins overrepresented in both groups of good stallions included a peroxiredoxin-6 like protein, and transcobalamin-2, a primary vitamin B12binding and transport protein. Also, the protein involved in protein glycosylation, ST3 beta-galactoside alpha-2,3-sialyltransferase 1 was present in the GOOD stallions. These proteins were nearly absent in POOR stallions (Fig 7). Following this, volcano plots were used to explore potential candidates that may explain differences between stallions, and revealed that poor stallions were characterized by low amounts of antioxidant proteins, particularly catalase, superoxide dismutase and peroxiredoxin 6 like protein (Fig $8 \mathrm{C}$ ); while good stallions presented high amounts of peroxiredoxin 6 like protein (Fig 8A) and annexin $A$ was enriched in stallions requiring SP-removal (Fig. 8B).

More specifically, and due to its practical importance, differences between stallions that need SP-removal to withstand refrigeration, from those that withstand cryopreservation after extension in the presence of SP were explored, focusing on which proteins were differentially expressed by two groups of stallions classed as: GOOD or RSP. In the volcano plots, two proteins (annexinA2 and spectrin beta chain) were underrepresented 
in GOOD stallions while overrepresented in RSP stallions (Fig 9a-b). In particular, annexinA2 revealed as a powerful discriminant variable to identify RSP-stallions, with a $p=0.002$ and a $q$ value $=0.005$. We used STRING to identify potential functional partners of this protein, and included Protein S100-A10, Kalirin, Obscurin, Plasminogen, Plasminogen activator, Trio Rho guanine nucleotide exchange factor, Annexin A11, Caspase 4 and Caspase 9 (Fig 9C).

\section{Discussion}

This study investigated the proteome of the SP in horses using a shot gun proteomics approach and a bioinformatic enrichment analysis. Although previous studies have addressed equine SP, this is, to the authors' knowledge, the first study focused not only on the detailed description of the SP-proteome but to link specific SP-proteins with the ability of the ejaculate to be stored chilled to $5^{\circ} \mathrm{C}$ for $48 \mathrm{~h}$. Enrichment analysis suggested the equine SP plays important roles in the metabolism of hexoses, extracellular vesicles and response to hydrogen peroxide, since these terms were significantly enriched. Hexose metabolism and extracellular vesicles are linked, acting as a support mechanism for spermatozoa. Prostasomes, a specific class of extracellular vesicles, express glycolytic enzymes with capacity for ATP production [41-43]. Interestingly the abundance of SPproteins involved in carbohydrate metabolism relates to stallion fertility [18] The proteins involved in these metabolic pathways are present in equine prostasomes [42] which links to the enrichment findings in our study. Another function of relevance in SP, enriched in our analysis, was the response to stress and to hydrogen peroxide. Catalase has been reported as a key antioxidant present in equine SP that is derived primarily from prostatic secretions[44]. In addition, in relation to redox regulation, the GO term NADH regeneration (GO:0006735) was significantly enriched in equine SP. Finally, another group of enriched terms were those related to post-transcriptional modification of proteins, particularly SUMOylation, with the reactome pathways SUMOylation and SUMO E3 ligases SUMOylate target proteins. Since the spermatozoa is a translationally and transcriptionally silent cell, they rely heavily on post translational modifications for their regulation $[45,46]$. This finding suggests a major role of SP in regulating sperm functionality; further supported by the study of functional networks. STRING analysis revealed, using the highest confidence threshold (0.900), a highly interconnected network of SP-proteins, providing a sound background for the assumption of roles in hexose metabolism, and post translational modifications of proteins in the network, particularly SUMOylation [47-50]

In addition to enrichment analysis, the proteome in 10 stallions routinely used in a commercial facility producing seminal doses was studied. They were classified in three groups according to the ability of their ejaculates to withstand extension and posterior conservation by refrigeration. Differences in the proteome among these groups were investigated, in an attempt to identify specific proteins or groups of proteins, that may explain the different life span of their ejaculates. Numerous proteins were less abundant in samples with a reduced life span under refrigeration, many of these proteins were related to redox regulation, including catalase, peroxiredoxin 6 , superoxide dismutase. Differences among stallions in the content of superoxide dismutase and glutathione peroxidases have been previously reported [51]. In addition, another protein with 
antioxidant activity, HSP-90 [52] was found to be less abundant in poor samples. Interestingly, alteration of redox regulation inactivates HPS-90 due to the action of reactive electrophilic aldehydes generated during the loss of redox homeostasis [53]. All together, these findings support the hypothesis that ineffective redox regulation is behind the limited period of time that these ejaculates can be conserved by refrigeration. Other proteins related to metabolism, like oxoglutarate dehydrogenase, glyceraldehyde 3 phosphate dehydrogenase or proteins involved in cell viability like PI3K were also reduced in this group of stallions. The total absence of the glucagon receptor, recently described in human spermatozoa, with stimulatory action of glucagon on lactate dehydrogenase and glucose-6-phosphate dehydrogenase (G6PDH) activities [54] in equine poor samples of the present study is particularly noted. This receptor fueled phosphatidylinositol-3-kinase (PI3K)/AKT signaling and was reversed by the protein kinase inhibitor $\mathrm{H} 89$, indicating a dependence of glucagon signaling on protein kinase $A$ (PKA).

Although peroxiredoxin 6 and catalase were as found to be mostabundant in good stallions, their levels did not differ from those in SRP-stallions, which makes them irrelevant as biomarkers. The protein ST3 beta-galactoside alpha-2,3-sialyltransferase 1 (ST3GAL1) was highly enriched in good stallions. This protein plays a role in posttranscriptional modification of proteins, and interestingly the gene for ST3GAL1 has previously been associated with sperm storage duration in the oviduct in chickens [55]. This finding falls in line with the special dependence of post transcriptional modifications for the proper functioning of the spermatozoa. The comparison between stallions that needed removal of most SP (good after RSP) and those not requiring this procedure (GOOD stallions) identified a number of proteins as better candidate bio-markers, with annexin highly enriched in SRP-stallions, while barely present in good stallions. Annexins have a wide variety of cellular functions, including cell proliferation, differentiation, apoptosis, migration, membrane repair and inflammatory response [56]. Although annexin can be considered a good potential marker to distinguish samples that will require SP-removal, the reasons behind this remain speculative; potential mechanisms involved may include increased inflammatory responses [57] or accelerated progression of apoptosis in these stallions [58,59]. Equine annexins may stimulate the production of reactive oxygen species, a mechanism involved in these responses [57]. The network analysis also supported this hypothesis, with annexin interacting with proteins involved in cell survival and immune regulation.

In conclusion, this study provides the first detailed description of the proteome of equine seminal plasma. Bioinformatic analysis revealed major roles related to hexose metabolism, that may be mediated by extracellular vesicles, probably involving prostasomes. In addition, findings are suggestive of major roles of SP in redox regulation and regulation of the immune response. The finding that the varied presence of specific proteins from groups of SP-proteins have potential value as markers for the ability of the ejaculates to withstand refrigeration, and whether or not they may need SP-removal to achieve this goal is of particular practical interest. Moreover, findings offer new potential lines of research, with applications both in sperm biotechnologies and reproductive medicine. 


\section{REFERENCES}

1. Pena FJ, Garcia BM, Samper JC, Aparicio IM, Tapia JA, Ferrusola CO. Dissecting the molecular damage to stallion spermatozoa: the way to improve current cryopreservation protocols? Theriogenology 2011; 76:1177-1186.

2. Brinsko SP, Crockett EC, Squires EL. Effect of centrifugation and partial removal of seminal plasma on equine spermatozoal motility after cooling and storage. Theriogenology 2000; 54:129-136.

3. Barrier-Battut I, Bonnet C, Giraudo A, Dubois C, Caillaud M, Vidament M. Removal of seminal plasma enhances membrane stability on fresh and cooled stallion spermatozoa. Reprod Domest Anim 2013; 48:64-71.

4. Kareskoski AM, Palviainen M, Johannisson A, Katila T. Upregulation of CRISP-3 and kallikrein in stallion seminal plasma is associated with poor tolerance of cooled storage. Reprod Domest Anim 2020.

5. Rodriguez-Martinez H, Kvist U, Ernerudh J, Sanz L, Calvete JJ. Seminal plasma proteins: what role do they play? Am J Reprod Immunol 2011; 66 Suppl 1:1122.

6. Kareskoski AM, del Alamo MM, Guvenc K, Reilas T, Calvete JJ, RodriguezMartinez $\mathrm{H}$, Andersson $\mathrm{M}$, Katila T. Protein composition of seminal plasma in fractionated stallion ejaculates. Reprod Domest Anim 2011; 46:e79-84.

7. Rodriguez-Martinez $H$, Kvist U, Saravia F, Wallgren M, Johannisson A, Sanz L, Pena FJ, Martinez EA, Roca J, Vazquez JM, Calvete JJ. The physiological roles of the boar ejaculate. Soc Reprod Fertil Suppl 2009; 66:1-21.

8. Calvete JJ, Sanz L. Insights into structure-function correlations of ungulate seminal plasma proteins. Soc Reprod Fertil Suppl 2007; 65:201-215.

9. Barrier-Battut I, Dacheux JL, Gatti JL, Rouviere P, Stanciu C, Dacheux F, Vidament $\mathrm{M}$. Seminal plasma proteins and semen characteristics in relation with fertility in the stallion. Anim Reprod Sci 2005; 89:255-258.

10. Fedorka CE, Scoggin KE, Woodward EM, Squires EL, Ball BA, Troedsson M. The effect of select seminal plasma proteins on endometrial mRNA cytokine expression in mares susceptible to persistent mating-induced endometritis. Reprod Domest Anim 2017; 52:89-96.

11. Troedsson MH, Desvousges A, Alghamdi AS, Dahms B, Dow CA, Hayna J, Valesco R, Collahan PT, Macpherson ML, Pozor M, Buhi WC. Components in seminal plasma regulating sperm transport and elimination. Anim Reprod Sci 2005; 89:171-186.

12. Alghamdi AS, Foster DN, Troedsson MH. Equine seminal plasma reduces sperm binding to polymorphonuclear neutrophils (PMNs) and improves the fertility of fresh semen inseminated into inflamed uteri. Reproduction 2004; 127:593-600.

13. Magdaleno L, Gasset M, Varea J, Schambony AM, Urbanke C, Raida M, TopferPetersen E, Calvete JJ. Biochemical and conformational characterisation of HSP3 , a stallion seminal plasma protein of the cysteine-rich secretory protein (CRISP) family. FEBS Lett 1997; 420:179-185.

14. Reinert M, Calvete JJ, Sanz L, Topfer-Petersen E. Immunohistochemical localization in the stallion genital tract, and topography on spermatozoa of seminal plasma protein SSP-7, a member of the spermadhesin protein family. Andrologia 1997; 29:179-186. 
15. Reinert M, Calvete JJ, Sanz L, Mann K, Topfer-Petersen E. Primary structure of stallion seminal plasma protein HSP-7, a zona-pellucida-binding protein of the spermadhesin family. Eur J Biochem 1996; 242:636-640.

16. Calvete JJ, Reinert M, Sanz L, Topfer-Petersen E. Effect of glycosylation on the heparin-binding capability of boar and stallion seminal plasma proteins. J Chromatogr A 1995; 711:167-173.

17. Calvete JJ, Mann K, Schafer W, Sanz L, Reinert M, Nessau S, Raida M, TopferPetersen E. Amino acid sequence of HSP-1, a major protein of stallion seminal plasma: effect of glycosylation on its heparin- and gelatin-binding capabilities. Biochem J 1995; 310 ( Pt 2):615-622.

18. Novak S, Smith TA, Paradis F, Burwash L, Dyck MK, Foxcroft GR, Dixon WT. Biomarkers of in vivo fertility in sperm and seminal plasma of fertile stallions. Theriogenology 2010; 74:956-967.

19. Fouchecourt S, Metayer S, Locatelli A, Dacheux F, Dacheux JL. Stallion epididymal fluid proteome: qualitative and quantitative characterization; secretion and dynamic changes of major proteins. Biol Reprod 2000; 62:17901803.

20. Castillo J, Jodar M, Oliva R. The contribution of human sperm proteins to the development and epigenome of the preimplantation embryo. Hum Reprod Update 2018; 24:535-555.

21. Codina M, Estanyol JM, Fidalgo MJ, Ballesca JL, Oliva R. Advances in sperm proteomics: best-practise methodology and clinical potential. Expert Rev Proteomics 2015; 12:255-277.

22. Amaral A, Paiva C, Attardo Parrinello C, Estanyol JM, Ballesca JL, RamalhoSantos J, Oliva R. Identification of proteins involved in human sperm motility using high-throughput differential proteomics. J Proteome Res 2014; 13:56705684.

23. Oliva R, Ballesca J. Proteomics of the spermatozoon. Balkan J Med Genet 2012; 15:27-30.

24. Oliva R, De Mateo S, Castillo J, Azpiazu R, Oriola J, Ballesca JL. Methodological advances in sperm proteomics. Hum Fertil (Camb) 2010; 13:263-267.

25. Swegen A, Curry BJ, Gibb Z, Lambourne SR, Smith ND, Aitken RJ. Investigation of the stallion sperm proteome by mass spectrometry. Reproduction 2015; 149:235-244.

26. Martin-Cano FE, Gaitskell-Phillips G, Ortiz-Rodriguez JM, Silva-Rodriguez A, Roman A, Rojo-Dominguez P, Alonso-Rodriguez E, Tapia JA, Gil MC, OrtegaFerrusola $C$, Pena FJ. Proteomic profiling of stallion spermatozoa suggests changes in sperm metabolism and compromised redox regulation after cryopreservation. J Proteomics 2020; 221:103765.

27. Jodar M, Soler-Ventura A, Oliva R, Molecular Biology of R, Development Research G. Semen proteomics and male infertility. J Proteomics 2017; 162:125-134.

28. Amaral A, Castillo J, Ramalho-Santos J, Oliva R. The combined human sperm proteome: cellular pathways and implications for basic and clinical science. Hum Reprod Update 2014; 20:40-62. 
29. Morrell JM, Garcia BM, Pena FJ, Johannisson A. Processing stored stallion semen doses by Single Layer Centrifugation. Theriogenology 2011; 76:14241432.

30. Ortega-Ferrusola C, Garcia BM, Gallardo-Bolanos JM, Gonzalez-Fernandez L, Rodriguez-Martinez H, Tapia JA, Pena FJ. Apoptotic markers can be used to forecast the freezeability of stallion spermatozoa. Anim Reprod Sci 2009; 114:393-403.

31. Mi H, Muruganujan A, Casagrande JT, Thomas PD. Large-scale gene function analysis with the PANTHER classification system. Nat Protoc 2013; 8:1551-1566.

32. Mi H, Muruganujan A, Thomas PD. PANTHER in 2013: modeling the evolution of gene function, and other gene attributes, in the context of phylogenetic trees. Nucleic Acids Res 2013; 41:D377-386.

33. Raudvere U, Kolberg L, Kuzmin I, Arak T, Adler P, Peterson H, Vilo J. g:Profiler: a web server for functional enrichment analysis and conversions of gene lists (2019 update). Nucleic Acids Res 2019; 47:W191-W198.

34. Du J, Yuan Z, Ma Z, Song J, Xie X, Chen Y. KEGG-PATH: Kyoto encyclopedia of genes and genomes-based pathway analysis using a path analysis model. Mol Biosyst 2014; 10:2441-2447.

35. Altermann E, Klaenhammer TR. PathwayVoyager: pathway mapping using the Kyoto Encyclopedia of Genes and Genomes (KEGG) database. BMC Genomics 2005; 6:60.

36. Ogata H, Goto S, Sato K, Fujibuchi W, Bono H, Kanehisa M. KEGG: Kyoto Encyclopedia of Genes and Genomes. Nucleic Acids Res 1999; 27:29-34.

37. Mi H, Muruganujan A, Huang X, Ebert D, Mills C, Guo X, Thomas PD. Protocol Update for large-scale genome and gene function analysis with the PANTHER classification system (v.14.0). Nat Protoc 2019; 14:703-721.

38. Bourgon R, Gentleman R, Huber W. Independent filtering increases detection power for high-throughput experiments. Proc Natl Acad Sci U S A 2010; 107:9546-9551.

39. Hochberg Y, Benjamini Y. More powerful procedures for multiple significance testing. Stat Med 1990; 9:811-818.

40. Ortega-Ferrusola C, Macias Garcia B, Suarez Rama V, Gallardo-Bolanos JM, Gonzalez-Fernandez L, Tapia JA, Rodriguez-Martinez H, Pena FJ. Identification of sperm subpopulations in stallion ejaculates: changes after cryopreservation and comparison with traditional statistics. Reprod Domest Anim 2009; 44:419423.

41. Ronquist GK, Ek B, Ronquist G, Morrell J, Carlsson L, Larsson A. Biochemical characterization of stallion prostasomes and comparison to their human counterparts. Syst Biol Reprod Med 2013; 59:297-303.

42. Ronquist KG, Ek B, Morrell J, Stavreus-Evers A, Strom Holst B, Humblot $P$, Ronquist $\mathrm{G}$, Larsson $A$. Prostasomes from four different species are able to produce extracellular adenosine triphosphate (ATP). Biochim Biophys Acta 2013; 1830:4604-4610.

43. Ronquist KG, Ek B, Stavreus-Evers A, Larsson A, Ronquist G. Human prostasomes express glycolytic enzymes with capacity for ATP production. Am J Physiol Endocrinol Metab 2013; 304:E576-582. 
44. Ball BA, Gravance CG, Medina V, Baumber J, Liu IK. Catalase activity in equine semen. Am J Vet Res 2000; 61:1026-1030.

45. Visconti PE, Kopf GS. Regulation of protein phosphorylation during sperm capacitation. Biol Reprod 1998; 59:1-6.

46. Pena FJ, O'Flaherty C, Ortiz Rodriguez JM, Martin Cano FE, Gaitskell-Phillips GL, Gil MC, Ortega Ferrusola C. Redox Regulation and Oxidative Stress: The Particular Case of the Stallion Spermatozoa. Antioxidants (Basel) 2019; 8.

47. Marchiani S, Tamburrino L, Ricci B, Nosi D, Cambi M, Piomboni P, Belmonte G, Forti G, Muratori M, Baldi E. SUMO1 in human sperm: new targets, role in motility and morphology and relationship with DNA damage. Reproduction 2014; 148:453-467.

48. Vigodner M, Shrivastava V, Gutstein LE, Schneider J, Nieves E, Goldstein M, Feliciano M, Callaway M. Localization and identification of sumoylated proteins in human sperm: excessive sumoylation is a marker of defective spermatozoa. Hum Reprod 2013; 28:210-223.

49. Marchiani S, Tamburrino L, Giuliano L, Nosi D, Sarli V, Gandini L, Piomboni P, Belmonte G, Forti G, Baldi E, Muratori M. Sumo1-ylation of human spermatozoa and its relationship with semen quality. Int J Androl 2011; 34:581593.

50. Shrivastava V, Pekar M, Grosser E, Im J, Vigodner M. SUMO proteins are involved in the stress response during spermatogenesis and are localized to DNA double-strand breaks in germ cells. Reproduction 2010; 139:999-1010.

51. Ortega Ferrusola C, Gonzalez Fernandez L, Morrell JM, Salazar Sandoval C, Macias Garcia B, Rodriguez-Martinez H, Tapia JA, Pena FJ. Lipid peroxidation, assessed with BODIPY-C11, increases after cryopreservation of stallion spermatozoa, is stallion-dependent and is related to apoptotic-like changes. Reproduction 2009; 138:55-63.

52. Zhang $M$, Wang D, Geng Z, Li P, Sun Z, Xu W. Effect of heat shock protein 90 against ROS-induced phospholipid oxidation. Food Chem 2018; 240:642-647.

53. Hall SE, Aitken RJ, Nixon B, Smith ND, Gibb Z. Electrophilic aldehyde products of lipid peroxidation selectively adduct to heat shock protein 90 and arylsulfatase A in stallion spermatozoa. Biol Reprod 2017; 96:107-121.

54. Rago V, De Rose D, Santoro M, Panza S, Malivindi R, Ando S, D'Agata R, Aquila S. Human Sperm Express the Receptor for Glucagon-like Peptide-1 (GLP-1), Which Affects Sperm Function and Metabolism. Endocrinology 2020; 161.

55. Yang L, Zheng X, Mo C, Li S, Liu Z, Yang G, Zhao Q, Li S, Mou C. Transcriptome analysis and identification of genes associated with chicken sperm storage duration. Poult Sci 2020; 99:1199-1208.

56. Grewal T, Wason SJ, Enrich C, Rentero C. Annexins - insights from knockout mice. Biol Chem 2016; 397:1031-1053.

57. Pickles KJ, Brooks AC, Rickards KJ, Cunningham FM. Expression of annexin-1 in equine leucocytes and the effects of the N-terminal annexin-1 peptide, Ac2-26, on equine neutrophil superoxide production. Vet Immunol Immunopathol 2010; 135:226-233.

58. Gallardo Bolanos JM, Miro Moran A, Balao da Silva CM, Morillo Rodriguez A, Plaza Davila M, Aparicio IM, Tapia JA, Ortega Ferrusola C, Pena FJ. Autophagy 
and apoptosis have a role in the survival or death of stallion spermatozoa during conservation in refrigeration. PLoS One 2012; 7:e30688.

59. Caselles AB, Miro-Moran A, Morillo Rodriguez A, Gallardo Bolanos JM, OrtegaFerrusola C, Salido GM, Pena FJ, Tapia JA, Aparicio IM. Identification of apoptotic bodies in equine semen. Reprod Domest Anim 2014; 49:254-262. 
Table 1.- Panther overrepresentation test of proteins of interest identified by UHPLC/MS/MS and gene ontology analysis of fresh equine (Equus caballus) spermatozoa

\begin{tabular}{|l|l|l|}
\hline GO Biological process & $\begin{array}{l}\text { Fold } \\
\text { Enrichment }\end{array}$ & P value \\
\hline hemoglobin metabolic process (GO:0020027) & 40.14 & $1.32 \mathrm{E}-04$ \\
\hline ATP generation from ADP (GO:0006757) & 21.15 & $1.28 \mathrm{E}-07$ \\
\hline glycolytic process (GO:0006096) & 21.15 & $1.28 \mathrm{E}-07$ \\
\hline ADP metabolic process (GO:0046031) & 16.81 & $5.05 \mathrm{E}-07$ \\
\hline $\begin{array}{l}\text { purine ribonucleoside diphosphate metabolic process } \\
\text { (GO:0009179) }\end{array}$ & 14.90 & $1.04 \mathrm{E}-06$ \\
\hline $\begin{array}{l}\text { purine nucleoside diphosphate metabolic process } \\
\text { (GO:0009135) }\end{array}$ & 14.90 & $1.04 \mathrm{E}-06$ \\
\hline pyruvate metabolic process (GO:0006090) & 14.57 & $1.20 \mathrm{E}-06$ \\
\hline $\begin{array}{l}\text { ribonucleoside diphosphate metabolic process } \\
\text { (GO:0009185) }\end{array}$ & 14.25 & $1.37 \mathrm{E}-06$ \\
\hline nucleoside diphosphate phosphorylation (GO:0006165) & 13.95 & $1.55 \mathrm{E}-06$ \\
\hline nucleotide phosphorylation (GO:0046939) & 13.66 & $1.77 \mathrm{E}-06$ \\
\hline cellular response to hydrogen peroxide (GO:0070301) & 12.32 & $8.74 \mathrm{E}-05$ \\
\hline response to hydrogen peroxide (GO:0042542) & 11.02 & $3.01 \mathrm{E}-05$ \\
\hline carbohydrate catabolic process (GO:0016052) & 10.86 & $1.54 \mathrm{E}-06$ \\
\hline nucleoside diphosphate metabolic process (GO:0009132) & 10.57 & $8.28 \mathrm{E}-06$ \\
\hline cellular response to antibiotic (GO:0071236) & 8.65 & $1.05 \mathrm{E}-04$ \\
\hline ATP metabolic process (GO:0046034) & 5.59 & $1.37 \mathrm{E}-04$ \\
\hline $\begin{array}{l}\text { cellular response to organic cyclic compound } \\
\text { (GO:0071407) }\end{array}$ & 4.16 & $1.16 \mathrm{E}-05$ \\
\hline carbohydrate metabolic process (GO:0005975) & 3.89 & $2.39 \mathrm{E}-05$ \\
\hline response to drug (GO:0042493) & 3.10 & $8.73 \mathrm{E}-05$ \\
\hline cellular component morphogenesis (GO:0032989) & 2.82 & $1.03 \mathrm{E}-04$ \\
\hline regulation of response to stress (GO:0080134) & 2.73 & $7.73 \mathrm{E}-06$ \\
\hline
\end{tabular}

PANTHER Overrepresentation Test (Released 20200407) GO Ontology database Released 2020-02-21 Fisher's Test

FDR $P<0.05$ 
Table 2.- Table 1.- Panther overrepresentation test (GO Cellular component complete) of proteins of interest identified by UHPLC/MS/MS and gene ontology analysis of fresh equine (Equus caballus) spermatozoa

\begin{tabular}{|l|l|l|}
\hline GO biological process & Fold Enrichment & $P$ value \\
\hline $\begin{array}{l}\text { immunological synapse } \\
\text { (GO:0001772) }\end{array}$ & 13.38 & $3.46 \mathrm{E}-04$ \\
\hline $\begin{array}{l}\text { mitotic spindle } \\
\text { (GO:0072686) }\end{array}$ & 6.76 & $1.19 \mathrm{E}-04$ \\
\hline $\begin{array}{l}\text { microtubule cytoskeleton } \\
\text { (GO:0015630) }\end{array}$ & 2.38 & $1.78 \mathrm{E}-04$ \\
\hline $\begin{array}{l}\text { cytoskeleton } \\
\text { (GO:0005856) }\end{array}$ & 2.31 & $2.01 \mathrm{E}-06$ \\
\hline $\begin{array}{l}\text { extracellular } \\
\text { (GO:0005615) }\end{array}$ & 2.23 & $2.06 \mathrm{E}-04$ \\
\hline $\begin{array}{l}\text { extracellular non- } \\
\text { (GO:0005576) }\end{array}$ & 1.98 & $1.36 \mathrm{E}-04$ \\
\hline $\begin{array}{l}\text { intracellular } \\
\text { membrane-bounded } \\
\text { organelle (GO:0043232) }\end{array}$ & 1.91 & $1.94 \mathrm{E}-07$ \\
\hline $\begin{array}{l}\text { non-membrane-bounded } \\
\text { organelle (GO:0043228) }\end{array}$ & 1.91 & $1.96 \mathrm{E}-07$ \\
\hline
\end{tabular}

PANTHER Overrepresentation Test (Released 20200407) GO Ontology database Released 2020-02-21 Fisher's Test

FDR $P<0.05$

Figure 1.- g:GOST multiquery Manhattan plot showing comparative enrichment analysis of stallion seminal plasma proteins. Gene Ontology terms (GO) for molecular function (MF) are in red, for Biological Process (BP) in orange, for cellular component (CC) in green. The $P$ values are depicted in the $y$ axis and more detailed in the result table below the image.

Figure 2.- g:GOST multiquery Manhattan plot showing comparative enrichment analysis of stallion seminal plasma proteins. Kyoto Encyclopedia of Genes and Genomes are depicted in red, Reactome pathways in dark blue and Wikipathways in light blue (both using human orthologs). The $P$ values are depicted in the $y$ axis and more detailed in the result table below the image.

Figure 3.- STRING network analysis of proteins in equine seminal plasma. Protein interaction (PPI) was set with the highest confidence threshold $(0.900)$ and a $P$ value $=7.06 \mathrm{e}-05$ (Fig 3). Functional enrichment domains included the reactome pathways, glycolysis (FDR $=0.00039)$, vesicle mediated transport (FDR $=0.00039)$, gluconeogenesis $(\mathrm{FDR}=0.003)$, neutrophil degranulation $(\mathrm{FDR}=0.0051)$, post-translational protein 
modification (FDR=0.0051), and binding and uptake of ligands by scavenger receptors (FDR=0.0051)

Figure 4A-C.- Thermo resistance test of the 10 stallions used in a commercial Al program used in the present study. Ejaculates were collected and split in two subsamples, one was extended in INRA 96 to $30 \times 10^{6} \mathrm{spm} / \mathrm{ml}$, and the other half was extended after removal of seminal plasma by centrifugation and chilled to $5^{\circ} \mathrm{C}$ for up to $48 \mathrm{~h}$. Sperm motility using computer assisted sperm analysis (CASA) classified stallions into three groups: good if motility after $48 \mathrm{~h}$ was $>50 \%$ and VCL was $>100 \mu \mathrm{m} / \mathrm{s}$, poor if motility after $48 \mathrm{~h}$ was $<50 \%$ and VCL was $<100 \mu \mathrm{m} / \mathrm{s}$ and good after removal of seminal plasma (RSP), if $48 \mathrm{~h}$ after centrifugation and removal of the bulk of seminal plasma, motility was $>50 \%$ and VCL was $>100 \mu \mathrm{m} / \mathrm{s}$.

Figure 5.- Heat map showing differences in the relative expression of seminal plasma proteins (fold change $>2$ ) in the group of good stallions (not needing removal of seminal plasma to maintain good motility after 48 hours of conservation). $P<0.05$

Figure 6.- Heat map showing the identification of discriminant variables (seminal plasma proteins) in the group of good stallions with a fold change $>2, P<0.05$ and $q=0.1$

Figure 7.- Heat map showing differences in the expression in the relative amount of seminal plasma proteins (fold change $>2$ ) between stallions tolerating (good) or not (poor) direct extension, $P<0.05$

Figure 8.- Vulcano plots showing proteins enriched or underrepresented in the three groups of stallions (A, good, B, good after removal of seminal plasma and C, poor). Representative proteins identified in each group are depicted

Figure 9.- Vulcano plots showing proteins with the highest power as discriminant variables between good and good after removal of seminal plasma stallions. AnnexinA2 apeared as a powerful discriminant variable to identify stallions needing removal of seminal plasma prior to chilled preservation, with a $p=0.002$ and a $q$ value $=0.005$. In $C$ STRING was used to identify potential functional partners of this protein. 